\title{
The Effect of Acid-Reducing Pharmacotherapy on the Severity of Nausea and Vomiting of Pregnancy
}

\author{
Simerpal Kaur Gill, ${ }^{1,2}$ Caroline Maltepe, ${ }^{1}$ Katayoon Mastali, ${ }^{1}$ and Gideon Koren ${ }^{1,2}$ \\ ${ }^{1}$ The Motherisk Program, The Hospital for Sick Children, 555 University Avenue, Toronto, ON, Canada M5G 1X8 \\ ${ }^{2}$ Department of Pharmacology, University of Toronto, Toronto, ON, Canada M5S 1A8 \\ Correspondence should be addressed to Gideon Koren, gkoren@sickkids.ca
}

Received 1 October 2008; Revised 25 March 2009; Accepted 12 May 2009

Recommended by William A. Grobman

Background. Heartburn and acid reflux (HB/RF) are associated with increased severity of nausea and vomiting. The ability of acidreducing drugs to reduce symptoms of nausea and vomiting of pregnancy has not been previously tested. Objective. To determine whether acid-reducing pharmacotherapy decreases the severity of NVP symptoms. Methods. We studied a cohort of women experiencing NVP, who were also experiencing HB/RF. Women were counseled to commence acid-reducing pharmacotherapy. The effectiveness of the acid-reducing medication in decreasing symptoms of both HB/RF and NVP was measured. Results. Acidreducing drugs resulted in significant decreases in PUQE $(9.6 \pm 3.0$ to $6.5 \pm 2.5, P<.0001)$ and well-being scores from the initial $(4.0 \pm 2.0)$ to the follow-up interview $(6.8 \pm 1.6, P<.0001)$. After intervention with acid-reducing pharmacotherapy, a reduction in acid symptoms correlated significantly with reduction in NVP $\left(R^{2}=0.72, P<.001\right)$. Conclusion. This is the first study to demonstrate that management of $\mathrm{HB} / \mathrm{RF}$ can reduce the severity of NVP.

Copyright (c) 2009 Simerpal Kaur Gill et al. This is an open access article distributed under the Creative Commons Attribution License, which permits unrestricted use, distribution, and reproduction in any medium, provided the original work is properly cited.

\section{Introduction}

Nausea and vomiting of pregnancy (NVP) is the most common medical condition in pregnancy, experienced by up to $80 \%$ of women [1]. NVP has been shown to severely affect a woman's quality of life and her ability to function, especially when improperly managed [2]. Antiemetics are usually successful in managing NVP; however, certain medical conditions or symptoms, such as heartburn and/or acid reflux (HB/RF), can exacerbate the severity of NVP [3].

Heartburn and/or acid reflux are common medical disorders; it has been estimated that the incidence of gastroesophageal reflux disorders in pregnancy ranges between $40 \%$ and $85 \%[4,5]$. Symptoms associated with gastroesophageal reflux disorders or dyspepsia may include heartburn, acid reflux, regurgitation, eructation, flatulence, stomach bloating, indigestion, and sensation of a lump in the throat and may even affect quality of sleep $[6,7]$. These aforementioned symptoms can occur any time during pregnancy, and the severity of symptoms ranges possibly as a result of gastrointestinal tract motility changes due to increased levels of circulating sex hormones [8]. Similar changes in gastric motility and dysrhythmias have been observed in women suffering from NVP [8].

In a recent prospective, cohort study, we demonstrated that women experiencing both NVP and heartburn and/or acid reflux $(n=194)$ experienced greater severity of NVP compared to women who did not have any heartburn and/or acid reflux $(N=188)$ after controlling for certain confounders [9]. Trends were observed with more women experiencing both heartburn and acid reflux classifying their NVP as severe compared to controls and compared to women only experiencing either heartburn or acid reflux [9]. However, presently no study has examined the effectiveness of acid-reducing pharmacotherapy on NVP symptoms.

The objective of this study was to quantify whether acid-reducing pharmacotherapy is effective in decreasing the severity of NVP in women experiencing HB/RF.

\section{Methods}

The Motherisk Program, located at the Hospital for Sick Children in Toronto, has a specialized helpline for the 
TABLE 1: Motherisk-pregnancy-unique quantification of emesis and nausea (PUQE) scoring system. The PUQE scale is a validated scoring system to quantify the severity of NVP based on quantification of the 3 physical symptoms of NVP (nausea, vomiting, and retching) [11].

\begin{tabular}{|c|c|c|c|c|c|}
\hline $\begin{array}{l}\text { How many hours in past } 24 \text { hours had } \\
\text { you felt nauseated/sick to stomach? }\end{array}$ & None (1) & 1 hour or less (2) & 2-3 hours (3) & $4-6$ hours $(4)$ & $>6$ hours $(5)$ \\
\hline $\begin{array}{l}\text { How many times in the past } 24 \text { hours } \\
\text { did you vomit? }\end{array}$ & $\geq 7$ times (5) & 5-6 times (4) & 3-4 times (3) & 1-2 times (2) & None (1) \\
\hline $\begin{array}{l}\text { How many times in the past } 24 \text { hours } \\
\text { did you experience gagging or } \\
\text { retching or dry heaves? }\end{array}$ & None (1) & 1-2 times (2) & 3-4 times (3) & $5-6$ times $(4)$ & $\geq 7$ times $(5)$ \\
\hline
\end{tabular}

management of NVP. Women from Canada and the US experiencing NVP can call a toll-free service (1-800-4368477 ) to receive pharmacological and nonpharmacological advice on the management of NVP. This evidence-based counseling is based on research and continuous systematic review of emerging clinical and experimental evidence [10].

For the purpose of the present study, we enrolled women counseled by the NVP Helpline from November, 2007 to June, 2008. The study group consisted of all women who experienced heartburn and/or acid reflux while suffering from NVP. As per our standard, evidence-based counseling [10], these women were advised by us to commence on acidreducing pharmacotherapy, and based on the severity of their $\mathrm{HB} / \mathrm{RF}$ symptoms and on previous pregnancy use, if any, antacids, histamine 2 blockers, or proton pump inhibitors were recommended. Additionally, as histamine 2 blockers are available over-the-counter in Canada, usually they are recommended initially. All women agreed to continue their antiemetic at the dose taken prior to adding the acidreducing medication. Women who changed their antiemetic dose were excluded from analysis.

A standard interview was conducted, where detailed quantification of symptoms was obtained using the following validated tools: (1) the Pregnancy-Unique Quantification of Emesis and nausea (PUQE) score [11] (Table 1); (2) the wellbeing score [12] ranging from 0-10 was recorded based on how the woman felt overall compared to how she felt before pregnancy; (3) a self-report of how the woman perceived her symptoms (mild, moderate, severe). In addition, we recorded the time of onset of the NVP symptoms, gravidity, maternal age at conception, gestational age at the initial interview, and at follow-up, medical conditions that are associated with increased severity of NVP, medication use and the severity of NVP in previous pregnancies.

A standard follow-up interview was subsequently conducted to determine PUQE and Well-being scores and to inquire as to the acid-reducing pharmacotherapy used. To determine the role of acid-reducing pharmacotherapy in decreasing the severity of NVP, women were asked to rate on a scale of $0-10$, the effectiveness of their medication in reducing their acid symptoms, and the effectiveness of this medication in reducing their NVP.

Paired $t$-test was used to compare the mean PUQE and Well-being scores between the initial and follow-up interviews. Linear regression was used to determine the relationship between the reduction in heartburn and acid reflux and NVP. Similarly, linear regression was also performed on the initial PUQE scores and the change in PUQE scores, and on the onset of NVP and the onset of symptoms of HB/RF.

Statistical analyses were conducted with the SigmaStat program version 3.1 (Systat Software Inc., 2000, Ill, USA).

\section{Results}

Of 140 women, there were 80 women who experienced $\mathrm{HB} / \mathrm{RF}$ but were not stabilized on antiemetics and therefore were excluded from our analysis. The final cohort consisted of 60 women with NVP: 14 experienced only heartburn, 35 experienced only acid reflux, and 11 reported on both heartburn and acid reflux. Of the women included in our analysis, the self-reported severity of NVP was as follows: $72 \%$ of women classified their NVP as severe, $19 \%$ as moderate, and $9 \%$ as mild.

Mean gestational ages at initial counseling and at followup were $9.6 \pm 3.8$ weeks and $12.4 \pm 2.1$ weeks, respectively. Mean gestational age at onsets of NVP was at $5.5 \pm 3.0$ weeks, and mean gestational age at which symptoms of $\mathrm{HB} / \mathrm{RF}$ occurred was $6.8 \pm 2.4$ weeks. Additionally, linear regression demonstrated that the onsets of NVP and HB/RF were significantly correlated $\left(R^{2}=0.25, P=.004\right)$.

There were no significant differences in PUQE scores of women excluded from the study and initial PUQE scores of women included in the study $(9.5 \pm 2.5$ and $9.6 \pm 3.0$, $P=.2376)$. Use of acid-reducing medication resulted in a significant decrease in PUQE scores at follow-up (from $9.6 \pm 3.0$ to $6.5 \pm 2.5, P<.0001$, Figure 1 ). Similarly, there was a significant improvement in the Well-being scores from the initial $(4.0 \pm 2.0)$ to the follow-up interview $(6.8 \pm 1.6$, $P<.0001$, Figure 2).

The most commonly used acid-reducing pharmacotherapy was histamine-2 blockers, used by two-thirds of women (40/60). Proton pump inhibitors were used by 13 out of 60 women, and other over-the-counter antacids were used by 7 out of 60 women. The mean effectiveness of acid-reducing pharmacotherapy rated by the women was 8.2 out of 10 , and the mean effectiveness of the acidreducing pharmacotherapy in reducing NVP was 7.7 out of 10 . Women noticed improvement, on average, 3-4 days after commencing acid-reducing pharmacotherapy. Linear regression demonstrated that a reduction in acid symptoms significantly predicted the reduction in NVP with the use of acid-reducing pharmacotherapy $\left(R^{2}=0.72, P<\right.$ .001 , Figure 3$)$. As the severity of PUQE increased, there was a greater reduction in PUQE scores after the use of 


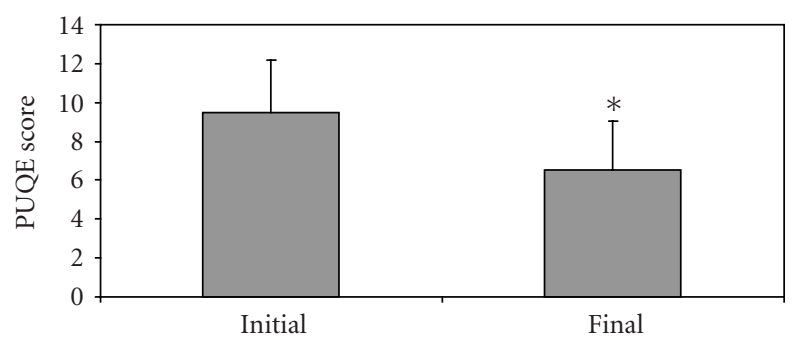

FIgURE 1: PUQE scores of women experiencing HB/RF and NVP at initial call and at follow-up after the use of acid-reducing pharmacotherapy; Final (marked “*”): $P<.0001$, compared to control.

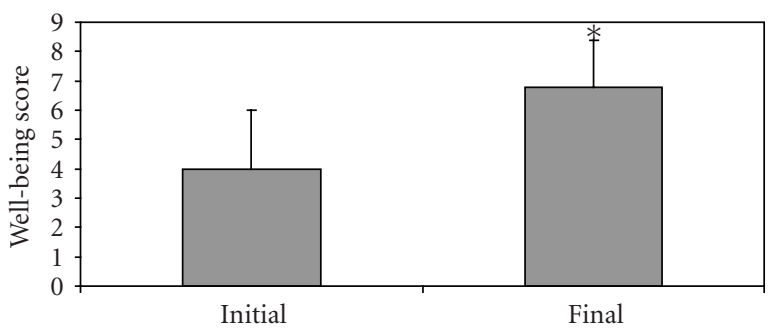

FIGURE 2: Well-being scores of women experiencing HB/RF and NVP at initial call and at follow-up after the use of acid-reducing pharmacotherapy; Final (marked “*”): $P<.0001$, compared to control.

acid-reducing pharmacotherapy as demonstrated by linear regression $\left(R^{2}=0.15, P=.003\right)$.

\section{Discussion}

Our data demonstrate for the first time that acid-reducing pharmacotherapy reduces the severity of NVP. There was a strong correlation between the reduction in acid symptoms and the reduction in the severity of NVP suggesting that treatment of $\mathrm{HB} / \mathrm{RF}$ will cause improvement in NVP. Women reported an improvement in both $\mathrm{HB} / \mathrm{RF}$ and NVP symptoms within 3 to 4 days after starting acid-reducing pharmacotherapy. Furthermore, women experiencing the most severe NVP had the greatest change in their NVP after using acid-reducing pharmacotherapy. These results support our initial observational study [9] in suggesting that $\mathrm{HB} / \mathrm{RF}$ is a significant contributor to NVP. Additionally, the onset of symptoms of NVP significantly correlated with the onset of symptoms of $\mathrm{HB} / \mathrm{RF}$ providing further evidence that $\mathrm{HB} / \mathrm{RF}$ exacerbates NVP.

Since withholding treatment was not considered ethical in the context of our clinical practice in the NVP healthline, our study could not recruit a cohort of women experiencing symptoms of $\mathrm{HB} / \mathrm{RF}$ who did not use acid-reducing pharmacotherapy. The lack of a comparison group is a limitation; however, the results from this pilot study provide valuable data for a future controlled study. To ensure, however, that the potential effect of acid-reducing drugs on NVP severity can be attributed to these medications, we excluded women who increased their antiemetics during the study.

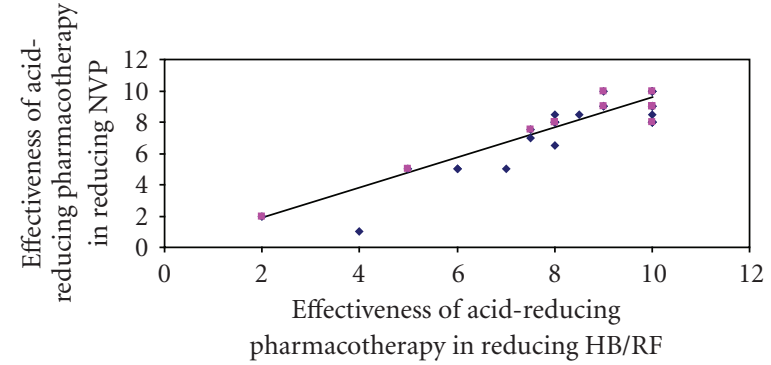

FIGURE 3: Linear regression comparing the effectiveness of acidreducing pharmacotherapy in reducing $\mathrm{HB} / \mathrm{RF}$, and in reducing NVP. Women rated effectiveness from zero (no effect) to 10 (maximal effect); $R^{2}=0.72, P<.001$.

This exclusion was done prior to evaluating the potential effects of acid suppressing drugs on the severity of NVP.

Nausea and vomiting of pregnancy and HB/RF result in adverse maternal outcomes including decreasing a woman's quality of life and her ability to function $[1,2]$, and more serious gastrointestinal morbidities such as gastroesophageal reflux disorder or peptic ulcers [13]. Treatment of HB/RF by histamine 2 blockers or proton pump inhibitors should be considered to alleviate symptoms, especially since these classes of drugs have been quite well studied in pregnancy, and have not been associated with increased fetal risks [1428].

\section{Acknowledgments}

Motherisk NVP helpline is supported by an unrestricted grant from Duchesnay, Inc. Canada. GK is holder of the Research Leadership for Better Pharmacotherapy during Pregnancy and Lactation (Hospital for Sick Children) and the Ivey Chair in Molecular Toxicology (Department of Medicine, University of Western Ontario). The study procedures received ethics approval from the Hospital for Sick Children ethics committee, the Research Ethics Board (REB). Ethics approval was obtained in May 22, 2008. The REB application number is 1000012298 .

\section{References}

[1] F. Miller, "Nausea and vomiting in pregnancy: the problem of perception-is it really a disease?" American Journal of Obstetrics and Gynecology, vol. 186, no. 5, pp. S182-S183, 2002.

[2] C. L. Attard, M. A. Kohli, S. Coleman, et al., "The burden of illness of severe nausea and vomiting of pregnancy in the United States," American Journal of Obstetrics and Gynecology, vol. 186, no. 5, pp. S220-S227, 2002.

[3] C. Louik, S. Hernandez-Diaz, M. M. Werler, and A. A. Mitchell, "Nausea and vomiting in pregnancy: maternal characteristics and risk factors," Paediatric and Perinatal Epidemiology, vol. 20, no. 4, pp. 270-278, 2006.

[4] T. H. Baron, B. Ramirez, and J. E. Richter, "Gastrointestinal motility disorders during pregnancy," Annals of Internal Medicine, vol. 118, no. 5, pp. 366-375, 1993. 
[5] R. A. R. Ali and L. J. Egan, "Gastroesophageal reflux disease in pregnancy," Best Practice \& Research Clinical Gastroenterology, vol. 21, no. 5, pp. 793-806, 2007.

[6] B. Geeraerts and J. Tack, "Functional dyspepsia: past, present, and future," Journal of Gastroenterology, vol. 43, no. 4, pp. 251$255,2008$.

[7] R. Tutuian and D. O. Castell, "Management of gastroesophageal reflux disease," American Journal of the Medical Sciences, vol. 326, no. 5, pp. 309-318, 2003.

[8] R. S. Fisher, G. S. Roberts, C. J. Grabowski, and S. Cohen, "Inhibition of lower esophageal sphincter circular muscle by female sex hormones," American Journal of Physiology, vol. 234, no. 3, pp. E243-E247, 1978.

[9] S. K. Gill, C. Maltepe, and G. Koren, "The effect of heartburn and acid reflux on the severity of nausea and vomiting of pregnancy," Canadian Journal of Gastroenterology, vol. 23, no. 4, pp. 270-272, 2009.

[10] A. Einarson, C. Maltepe, R. Boskovic, and G. Koren, "Treatment of nausea and vomiting in pregnancy: an updated algorithm," Canadian Family Physician, vol. 53, no. 12, pp. 2109-2111, 2007.

[11] G. Koren, R. Boskovic, M. Hard, C. Maltepe, Y. Navioz, and A. Einarson, "Motherisk-PUQE (pregnancy-unique quantification of emesis and nausea) scoring system for nausea and vomiting of pregnancy," American Journal of Obstetrics and Gynecology, vol. 186, no. 5, pp. S228-S231, 2002.

[12] G. Koren, C. Piwko, E. Ahn, et al., "Validation studies of the Pregnancy Unique-Quantification of Emesis (PUQE) scores," Journal of Obstetrics and Gynaecology, vol. 25, no. 3, pp. 241244, 2005.

[13] E. Rey, F. Rodriguez-Artalejo, M. A. Herraiz, et al., "Gastroesophageal reflux symptoms during and after pregnancy: a longitudinal study," American Journal of Gastroenterology, vol. 102, no. 11, pp. 2395-2400, 2007.

[14] H. Garbis, E. Elefant, O. Diav-Citrin, et al., "Pregnancy outcome after exposure to ranitidine and other H2-blockers: a collaborative study of the European Network of Teratology Information Services," Reproductive Toxicology, vol. 19, no. 4, pp. 453-458, 2005.

[15] L. A. Magee, G. Inocencion, L. Kamboj, F. Rosetti, and G. Koren, "Safety of first trimester exposure to histamine $\mathrm{H}_{2}$ blockers. A prospective cohort study," Digestive Diseases and Sciences, vol. 41, no. 6, pp. 1145-1149, 1996.

[16] A. Ruigómez, L. A. García Rodríguez, C. Cattaruzzi, et al., "Use of cimetidine, omeprazole, and ranitidine in pregnant women and pregnancy outcomes," American Journal of Epidemiology, vol. 150, no. 5, pp. 476-481, 1999.

[17] I. Matok, R. Gorodischer, G. Koren, and A. Levy, "The safety of intrauterine exposure to H2-blockers: a study by linking computerized databases," in Proceedings of the 11th Congress of the European Society for Developmental Pharmacology, Rotterdam, The Netherlands, June 2008, abstract no. 45.

[18] D. G. Colin Jones, M. J. S. Langman, D. H. Lawson, and M. P. Vessey, "Post-marketing surveillance of the safety of cimetidine: twelve-month morbidity report," Quarterly Journal of Medicine, vol. 54, no. 215, pp. 253-268, 1985.

[19] B. Kallen, "Delivery outcome after the use of acid-suppressing drugs in early pregnancy with special reference to omeprazole," British Journal of Obstetrics and Gynaecology, vol. 105, no. 8, pp. 877-881, 1998.

[20] A. Lalkin, R. Loebstein, A. Addis, et al., "The safety of omeprazole during pregnancy: a multicenter prospective controlled study," American Journal of Obstetrics and Gynecology, vol. 179, no. 3, pp. 727-730, 1998.
[21] G. Koren and D. M. Zemlickis, "Outcome of pregnancy after first trimester exposure to $\mathrm{H}_{2}$ receptor antagonists," American Journal of Perinatology, vol. 8, no. 1, pp. 37-38, 1991.

[22] J. D. Larson, E. Patatanian, P. B. Miner Jr., W. F. Rayburn, and M. G. Robinson, "Double-blind, placebo-controlled study of ranitidine for gastroesophageal reflux symptoms during pregnancy," Obstetrics and Gynecology, vol. 90, no. 1, pp. 8387, 1997.

[23] G. L. Nielsen, H. T. Sørensen, A. M. Thulstrup, U. TageJensen, C. Olesen, and A. Ekbom, "The safety of proton pump inhibitors in pregnancy," Alimentary Pharmacology and Therapeutics, vol. 13, no. 8, pp. 1085-1089, 1999.

[24] S. K. Gill, L. O’Brien, T. R. Einarson, and G. Koren, “The safety of proton pump inhibitors (PPIs) in pregnancy: a metaanalysis," The American Journal of Gastroenterology, vol. 104, no. 6, pp. 1541-1545, 2009.

[25] O. Diav-Citrin, J. Arnon, S. Shechtman, et al., "The safety of proton pump inhibitors in pregnancy: a multicentre prospective controlled study," Alimentary Pharmacology and Therapeutics, vol. 21, no. 3, pp. 269-275, 2005.

[26] I. Matok, R. Gorodischer, G. Koren, and A. Levy, “The safety of intrauterine exposure to proton pump inhibitors during the first trimester of pregnancy," in Proceedings of the 9th World Conference on Clinical Pharmacology and Therapeutics, Quebec, Canada, July 2008, abstract no. T3T124.

[27] B. A. J. Källén, "Use of omeprazole during pregnancyno hazard demonstrated in 955 infants exposed during pregnancy," European Journal of Obstetrics \& Gynecology and Reproductive Biology, vol. 96, no. 1, pp. 63-68, 2001.

[28] S. Nikfar, M. Abdollahi, M. E. Moretti, L. A. Magee, and G. Koren, "Use of proton pump inhibitors during pregnancy and rates of major malformations: a meta-analysis," Digestive Diseases and Sciences, vol. 47, no. 7, pp. 1526-1529, 2002. 


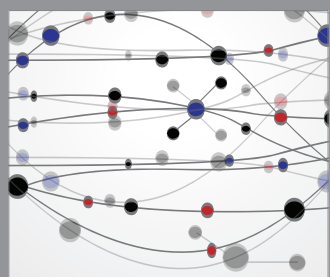

The Scientific World Journal
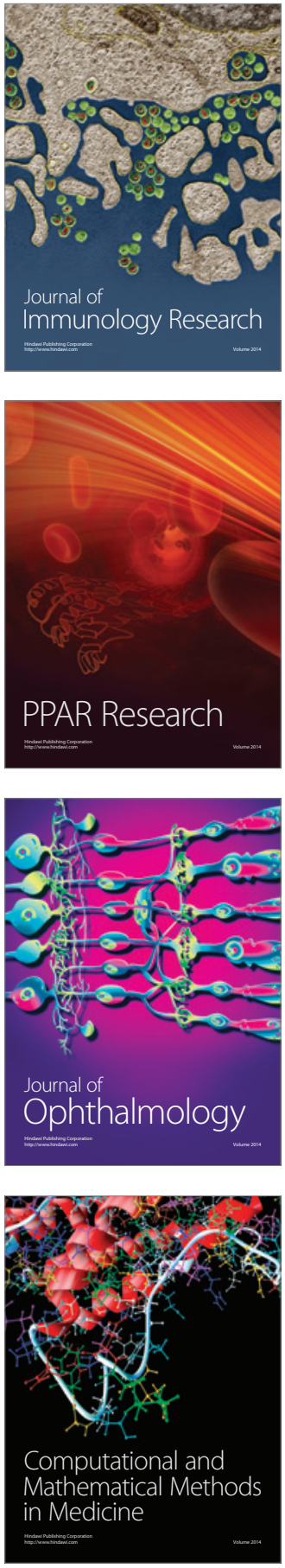

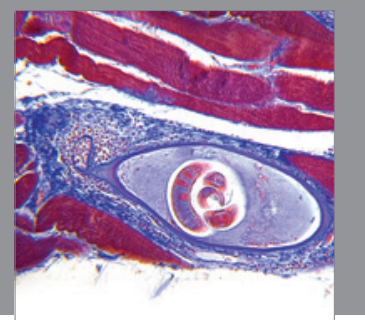

Gastroenterology

Research and Practice
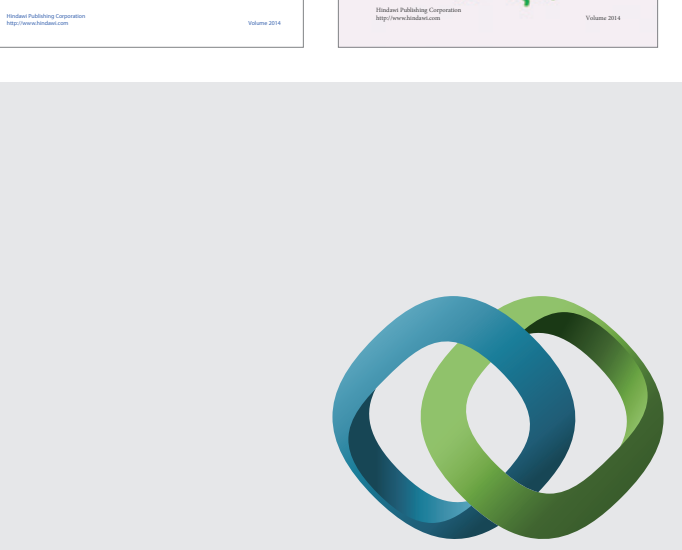

\section{Hindawi}

Submit your manuscripts at

http://www.hindawi.com
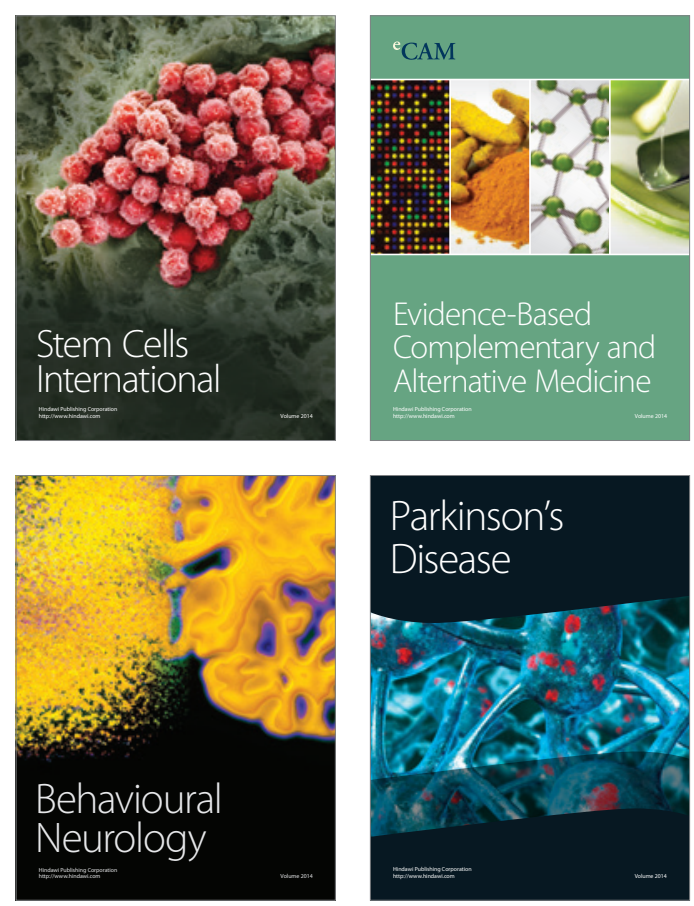

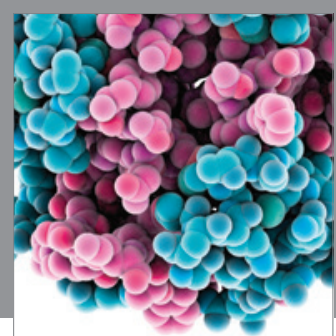

Journal of
Diabetes Research

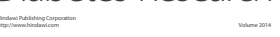

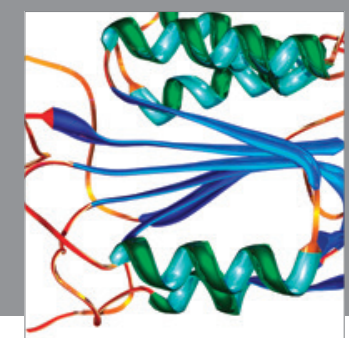

Disease Markers
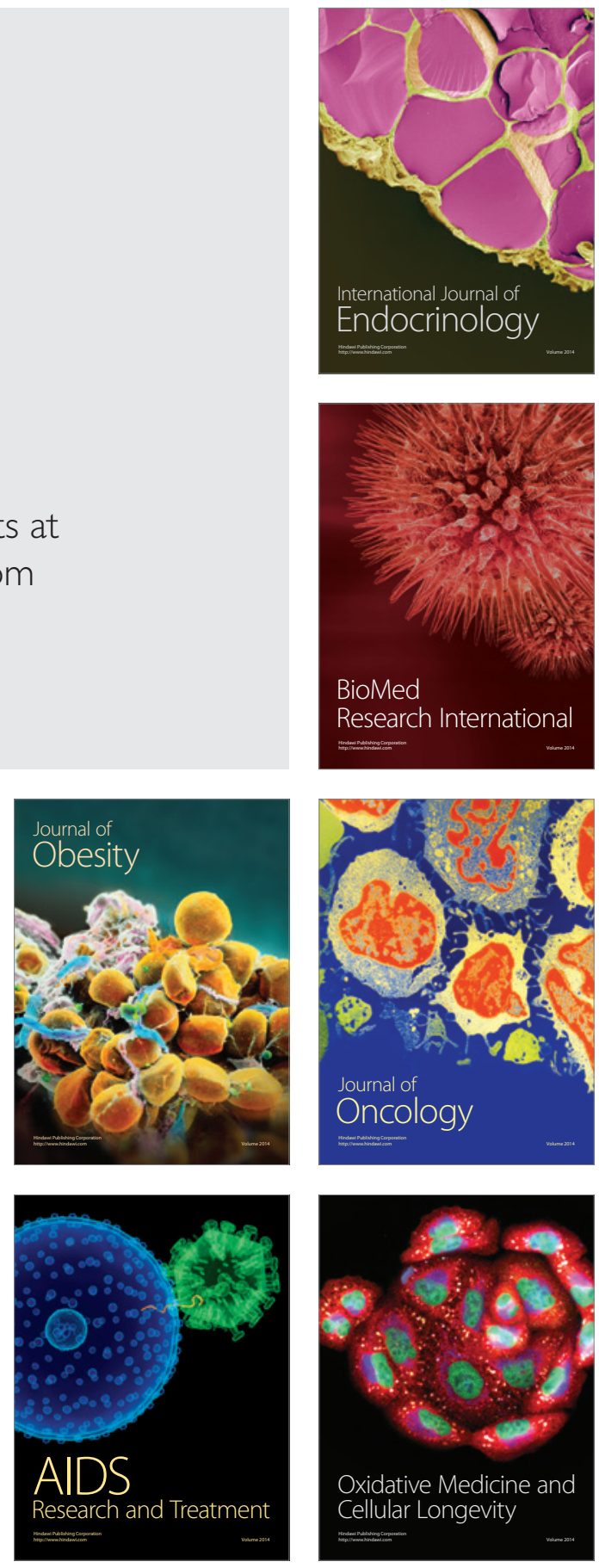